This item was submitted to Loughborough's Research Repository by the author.

Items in Figshare are protected by copyright, with all rights reserved, unless otherwise indicated.

\title{
The use of language to express thermal sensation suggests heat acclimatization by Indonesian people
}

PLEASE CITE THE PUBLISHED VERSION

http://dx.doi.org/10.1007/s00484-011-0519-1

PUBLISHER

(c) Springer Verlag

VERSION

AM (Accepted Manuscript)

LICENCE

CC BY-NC-ND 4.0

\section{REPOSITORY RECORD}

Tochihara, Yutaka, Joo-Young Lee, Hitoshi Wakabayashi, Titis Wijayanto, Ilham Bakri, and Ken Parsons. 2019. "The Use of Language to Express Thermal Sensation Suggests Heat Acclimatization by Indonesian People”. figshare. https://hdl.handle.net/2134/11801. 
This item was submitted to Loughborough's Institutional Repository (https://dspace.lboro.ac.uk/) by the author and is made available under the following Creative Commons Licence conditions.

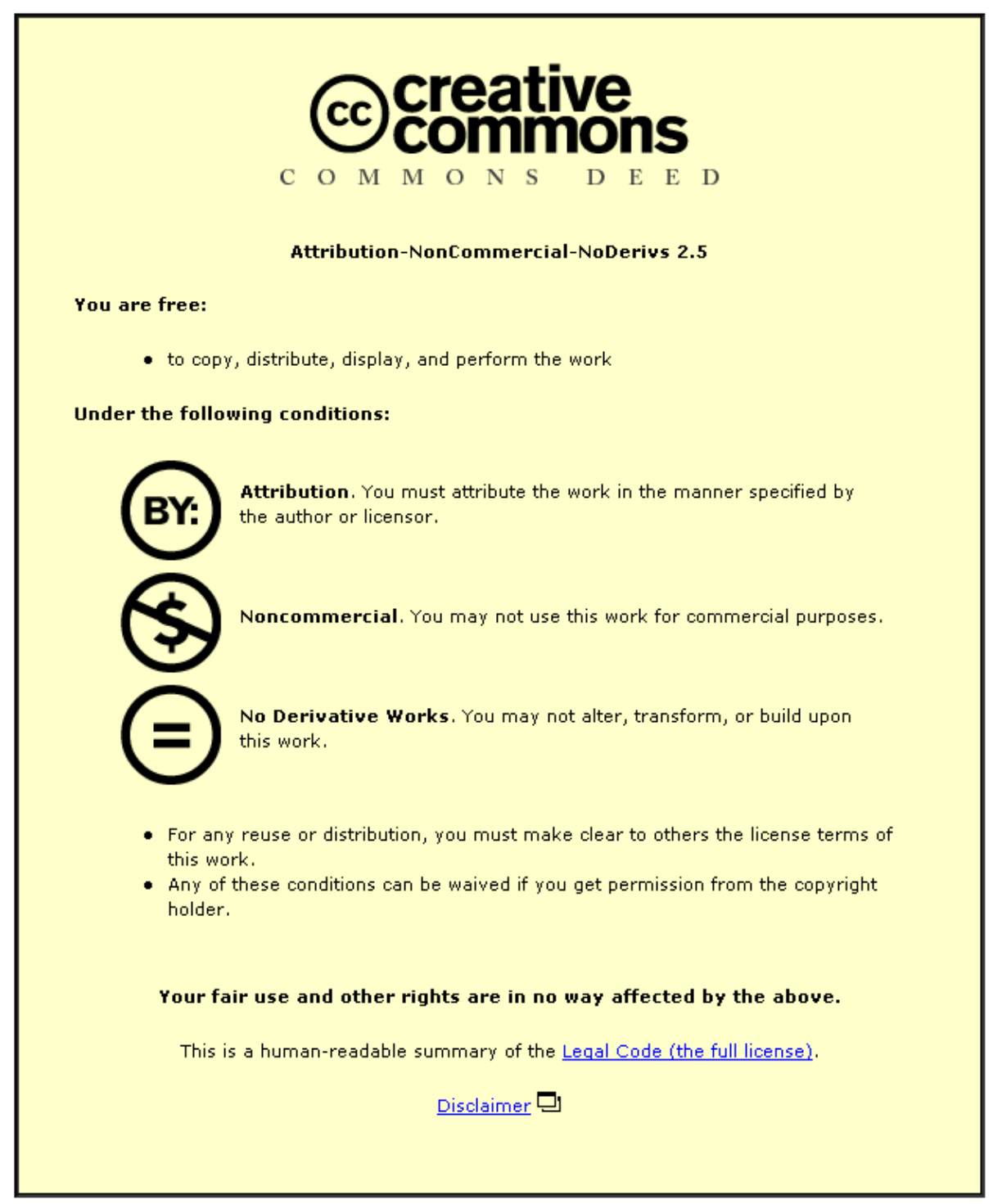

For the full text of this licence, please go to: http://creativecommons.org/licenses/by-nc-nd/2.5/ 


\title{
The Use of Language to Express Thermal Sensation Suggests Heat Acclimatization by Indonesian People
}

(Running head: Heat acclimatization in Indonesian Language)

\author{
Yutaka Tochihara $^{1)}$, Joo-Young Lee ${ }^{1) *}$, Hitoshi Wakabayashi ${ }^{1)}$, Titis Wijayanto ${ }^{1), 2)}$, \\ Ilham Bakri ${ }^{1,3)}$, Ken Parsons ${ }^{4)}$ \\ (Initials: Tochihara Y, Lee JY, Wakabayashi H, Wijayanto T, Bakri I, Parsons K)
}

1) Department of Human Science, Kyushu University, Japan

2) Department of Mechanical and Industrial Engineering, Gadjah Mada University, Indonesia

3) Industrial Engineering Department, Hasanuddin University, Indonesia

4) Loughborough Design School, Loughborough University, UK

Correspondence: Joo-Young Lee, Ph.D

Environmental Ergonomics Laboratory

Department of Human Science, Kyushu University, 4-9-1, Shiobaru Minami-ku Fukuoka 815-8540 Japan

Tel: +81-92-553-9493 (Office)

Fax: +81-92-553-4522

Email: leex3140@design.kyushu-u.ac.jp 


\title{
The Use of Language to Express Thermal Sensation Suggests Heat Acclimatization by Indonesian People
}

\begin{abstract}
The purpose of this study was to explore whether there is evidence of heat acclimatization in the words used to express thermal sensation. A total of 458 urban Japanese and 601 Indonesians participated in a questionnaire. In addition in a preliminary survey, 39 native English speakers in the UK participated. Our results showed that 1) for Indonesians, the closest thermal descriptor of a feeling of thermal comfort was 'cool' (75\%) followed by 'slightly cool’ (7\%), 'slightly cold’ (5\%) and ‘cold’ (5\%), while Japanese responses were uniformly distributed among descriptors ‘cool’, ‘slightly cool', 'neither', 'slightly warm', and 'warm'; 2) the closest thermal descriptors, of a feeling of discomfort, for Indonesians were less affected by individual thermal susceptibility (vulnerability) than those for Japanese; 3) in the cases where 'cool' and 'slightly cold' were imagined in the mind, the descriptors were cognized as a thermal comfortable feeling by $97 \%$ and $57 \%$ of Indonesians, respectively; 4) the most frequently voted choice endorsing hot weather was 'higher than $32^{\circ} \mathrm{C}$ ' for Indonesians and 'higher than $29^{\circ} \mathrm{C}$ ' for Japanese respondents; For cold weather, 'lower than $15^{\circ} \mathrm{C}$ ' for Japanese and 'lower than $20^{\circ} \mathrm{C}$ ' for Indonesians. In summary, the descriptor 'cool' in Indonesians connotes a thermally comfortable feeling, but the inter-zone between hot and cold weather that was judged in the mind showed a upward shift when compared to that of Japanese. It is suggested that linguistic heat acclimatization exists on a cognitive level for Indonesians and is preserved in the words of thermal descriptors.
\end{abstract}

Key words Heat acclimatization · Thermal sensation · Thermal comfort · Language · Behavioral thermoregulation 


\section{Introduction}

Acclimatization is defined as physiological or behavioral changes occurring within the lifetime of an organism that reduce the strain caused by stressful changes in natural climate (IUPS, 2001). Heat acclimatization is triggered as a response to a variety of complex environmental factors in hot climates. Over the past half century, a number of studies on heat acclimatization have been reported in terms of physiological adaptation (Lee et al., 2011b; Saat and Tochihara, 2008; Taylor, 2006; Wakabayashi et al., 2011; Wijayanto et al., 2011). Though heat acclimatization in psycho-physiological traits has been a relatively neglected area of research, several interesting studies have been conducted. Lee et al. (2010a) found that Malaysians had a tendency to perceive warmth at a higher skin temperature and at a slower rate at an identical speed of warming than Japanese, and they also had a wider range of the inter-threshold sensory zone than Japanese. These results were verified even for tropical indigenes who have resided in temperate climates for $\sim 5$ years (Lee et al., 2011a). Thermal receptors (thermal nerve fibers) transmit information about the temperature of the external surface of the body (Iggo, 1970; Schepers and Ringkamp, 2009), and then mediate the autonomic temperature regulation as well as generating thermal comfort through the integration of thermal sensations (Hensel, 1973; Hensel, 1982; Nadel et al., 1973). Perceived thermal sensation drives our thermoregulatory behavior, such as controlling air conditioning systems, changing clothes and postures, drinking, eating, and seeking comfortable shelter. These behaviors extend the homeostatic range in a hostile environment beyond the range of internal physiological reactions.

Whilst thermal stimuli that imposed on the body operate physiological effector mechanisms, such as shivering or sweating, the thermal perception is cognized finally through 'words' in the mind. Typically, the scales used to measure thermal sensation have been formatted as categorical scales such as cold, cool, slightly cool, neutral, slightly warm, warm, and hot (ASHRAE, 1992; Lee et al., 2010b). It is reasonable to assume that there will be variable linguistic dimensions in thermal sensation descriptors among different ethnic groups because there are a variety of climates on earth. ISO 10551 (1995) pointed out that bias will result from the vocabulary choices in each language when using thermal sensation scales. There are a couple of interesting approaches on the effects of language on the interpretation of words in thermal perception scales. 
Pitts (2006) stated that in translation the phrases may come to have different meanings to those implied in the English language when comparing English, Chinese, Greek and Arabic language groups. Humphreys (2008) compared the ASHRAE thermal sensation scale in five languages (English, French, Greek, Portuguese and Swedish) and concluded that words used in the ASHRAE scale do not have the same meaning in the different languages.

However, there has been little interest in relationships between the semantics of words describing thermal sensation and climatic backgrounds. Moreover, the concept of a 'linguistic thermal acclimatization' may sound like an unfamiliar issue. Lee et al. (2009) postulated that for Koreans in a hot and humid summer, the term 'slightly hot' is preferred over the term 'warm' because the word 'warm' in Korean conveys a sense of being thermally comfortable. The hypothesis was confirmed through a comprehensive survey on Koreans (Lee and Tochihara, 2010). However, it is not likely that the difference in the descriptor 'warm' between English and Korean language reflects the influence of heat or cold acclimatization, because Korea is located in a moderate climatic zone. In terms of climatic acclimatization, the comparative study on words expressing thermal sensation is an undeveloped issue. A word has its corresponding meaning in an individual's mental lexicon. It is both interesting and original to unveil whether there is refraction in languages and semantics expressing thermal sensation according to heat acclimatization. Exploration on heat acclimatization in languages would, rather, elucidate relationships between thermoregulatory behavior and subjective thermal perception. This approach will also contribute to discussions on the human being's adaptive nature which is unable to be found from animal research.

The purpose of this study was, therefore, to investigate whether there are semantic differences in different languages expressing thermal sensation between tropical (Indonesian) and temperate indigenes (Japanese). A preliminary survey from native English speakers in the UK was used as a reference value. Our hypothesis was that the closest descriptor among thermal descriptors for Indonesians of a feeling of thermal comfort is the term 'cool', but is not for Japanese. The understanding of thermal descriptors that are used in tropical and temperate climates will provide a more multilateral view in the research of behavioral thermoregulation. 


\section{Methods}

Characteristics of the survey respondents: A total of 458 Japanese (200 males and 258 females) and 601 Indonesians (342 males and 259 females) took part in this survey. Japanese respondents had a mean (SD) of 21.7 (3.7) yrs in age, 163.6 (9.6) cm in height, 54.7 (9.7) kg in body weight, and 20.4 (5.2) in body mass index (BMI); for Indonesians, 21.2 (5.2) years of age, 165.2 (8.3) cm in height, 59.3 (13.1) kg in weight, and 21.6 (3.7) in BMI. Ninety three percent of Japanese respondents were university members (e.g., undergraduate, graduate students and lecturers) in Fukuoka, Japan and so were 97\% of Indonesian respondents in Yogyakarta, Indonesia. Ninety eight percent of Japanese respondents have air conditioning systems equipped at home for both cooling and warming, while Indonesian respondents had no heating system at home. Indonesia is an equatorial country and the climate is characterized by wet and dry seasons with a minimal seasonal variation. Yogyakarta has an annual mean ambient temperature of $28^{\circ} \mathrm{C}$ with a relative humidity of 70 to $90 \%$. Japan is located in a temperate zone and Fukuoka has a moderate climate with an annual ambient temperature of $17^{\circ} \mathrm{C}$ and a relative humidity of $69 \%$. The survey protocol and questionnaire were approved by the Institutional Review Board of Kyushu University. At present, thermal sensation scales in the ASHRAE and ISO are presented in English. English is considered an international standard language on earth. In this sense, it is significant to have the English respondents as a reference group between Indonesian and Japanese people. However, people, who use English as their own first language, are dispersed all over the earth. Even in the USA there are significant longitudinal differences found from subarctic (Alaska) to subtropical climates (Florida or Hawaii). Hence, at this time we selected a small number of English people living in UK as a preliminary survey. A total of 39 native English speakers residing in the UK (Loughborough) participated in the present study [17 males and 22 females; Mean (SD), 20.8 (0.8) yrs in age].

\section{Questionnaire construction and procedures:}

Our hypothesis was that the closest descriptor among thermal descriptors for Indonesians of a feeling of thermal comfort is the term 'cool', but not in Japanese. The questionnaire consisted of a total of fourteen 
questions to test the hypothesis (Fig. 1) with three additional questions to gain information on daily heating and cooling habits (Q.1 and Q.2) and thermal susceptibility (Q. 3: I am particularly sensitive to cold, heat, both or neither). In particular, eight questions (question 5 to 12) were constructed based on the concept of conditional probability: $\mathrm{P}(\mathrm{A} \mid \mathrm{B})$, as introduced in Lee and Tochihara (2010). $\mathrm{P}(\mathrm{A} \mid \mathrm{B})$ is the probability of an event A, given the occurrence of another event B. Our hypothesis was bilaterally examined using the concept of conditional probability in both $\mathrm{P}(\mathrm{A} \mid \mathrm{B})$ and $\mathrm{P}(\mathrm{B} \mid \mathrm{A})$, where event $\mathrm{W}=$ 'I feel warm', event $\mathrm{SH}=$ ' $\mathrm{I}$ feel slightly hot', event C = 'I feel cool', event SC = 'I feel slightly cool', event SCD = 'I feel slightly cold', event S = 'I am thermally satisfied', and event DS = 'I am thermally dissatisfied'. Out of the eight questions, Question 5 was derived for getting $\mathrm{P}(\mathrm{S} \mid \mathrm{SH})$, Question 6 for $\mathrm{P}(\mathrm{S} \mid \mathrm{W})$, Question 7 for $\mathrm{P}(\mathrm{S} \mid \mathrm{SCD})$, Question 8 for $\mathrm{P}(\mathrm{S} \mid \mathrm{C})$, Question 9 for $\mathrm{P}(\mathrm{SH} \mid \mathrm{DS})$, Question 10 for $\mathrm{P}(\mathrm{SH} \mid \mathrm{S})$, Question 11 for $\mathrm{P}(\mathrm{C} \mid \mathrm{DS})$, and Question 12 for $\mathrm{P}(\mathrm{C} \mid \mathrm{S})$. Question 5 was inversely constructed in the relevance with Question 9. So were Question 6 vs. 10; Question 7 vs. 11; Question 8 vs. 12. Nine of the 11 categorical descriptors in the example box of Figure 1 were adopted from ISO 10551 (1995). Two other descriptors ('slightly cold’ and 'slightly hot') were based on common Japanese and Korean usage. In the present study the term 'neither', as one of thermal descriptors, is equivalent to 'not hot or cold', which is expressed as the term 'neutral'. All questions in the survey were written and asked in Japanese, Indonesian and English for each respondent and all words to describe thermal sensation in three languages were displayed in Table 1. Japanese and Indonesian languages have their own corresponding terms to each thermal descriptor in English. Only the word, 'neutral' in English, has been translated into 'neither hot nor cold' in Japanese and Indonesian languages. In Question 16 and 17, the intervals among categories were decided through our preliminary survey. The survey was conducted indoors Sep 2010 in Indonesia and Oct to Dec 2010 in Japan. The preliminary survey in the UK was conducted in March 2011. In the present study, terms ' $\mathrm{Cool}_{\mathbf{J}}$ ' and ' $\mathrm{cool}_{\mathbf{I}}$ ' stand for 'cool' in Japanese and 'cool' in Indonesian, respectively. The same applies to other thermal descriptors. Respondents were well-informed of precautions they should take, such as to express their general thoughts on questions, irrespective of the season when the survey was conducted. The validity of the present method to have subjects imagine certain thermal states (Question 5 to 12) was discussed in Lee and Tochihara (2010). 
Data analysis: Frequencies of responses for each question were analyzed. The frequencies were expressed as percentages of total frequencies. Missing values were removed from the counting of total responses. The percentages of responses for Questions 4 to 12 were interpreted with the concept of conditional probability. The group difference in frequencies between Japanese and Indonesians was tested by the chi-square test in Cross-tabulation analysis using SPSS v. 19.0. Responses from the English were omitted from the group comparison due to its relatively small sample size. Significance was set at $P<0.05$.

\section{Results}

The closest thermal description of a feeling of thermal comfort (Q.4): For the English, the closest descriptors of thermal comfort were 'slightly warm’ (33\%), followed by 'warm’ (15\%), 'cool’ (15\%), 'slightly cool' (13\%) and 'not hot or cold' (13\%). The responses to Question 4 showed a significant difference between Japanese and Indonesians $(P<0.001$, Fig. 2). For Indonesians the closest descriptors of

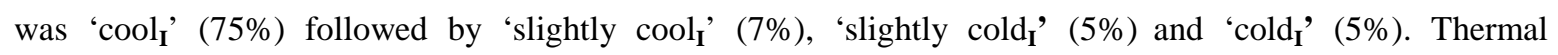
descriptors describing coolness or cold occupied 92\% of total Indonesian responses, while only $4 \%$ of Indonesian respondents expressed descriptors on the warm side (slightly warm, warm, slightly hot, and hot) as the closest descriptor of thermal comfortable feeling. On the other hand, Japanese's responses were relatively

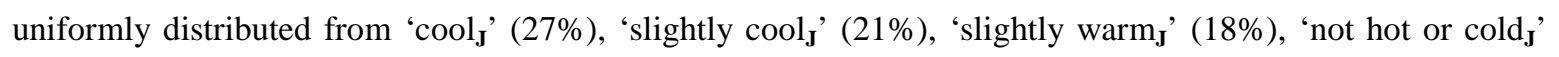
(16\%) and 'warm了' (14\%).

\section{The closest thermal description of a feeling of thermal comfort by individual thermal susceptibilities (Q.4}

by Q.3): The results from the English are not provided here since Question 3 was not asked for the preliminary survey with the English. Among Japanese respondents, 31\% ( $\mathrm{N}=144)$ and 22\% $(\mathrm{N}=100)$ were classified as cold and heat susceptible (vulnerable) individuals, respectively. For Indonesians, 24\% (N = 143) and $24 \%(\mathrm{~N}=144)$ of respondents were classified as cold and heat susceptible individuals, respectively. Eighteen percent of cold susceptible Japanese considered the term ' $\mathrm{cool}_{\mathbf{J}}$ ' as being the closest feeling of 
thermal comfort, whereas $40 \%$ of heat susceptible Japanese individuals expressed the term ' $\mathrm{cool}_{\mathbf{J}}$ ' as being the closest thermal comfortable feeling (Fig. 3). On the other hand, greater than $70 \%$ of both cold and heat susceptible (vulnerable) Indonesians expressed the term ' $\mathrm{cool}_{\mathbf{I}}$ ' as being the closest feeling of thermal comfort. In particular, $9 \%$ and $12 \%$ out of heat susceptible Indonesians considered the term 'slightly cold ${ }_{\mathbf{I}}$ ' and 'cold $\mathbf{I}$ ', respectively, as being the closest thermal comfortable feeling (Fig. 3). The difference between Japanese and Indonesians in respect to thermal susceptibility was significant $(P<0.001)$.

Interpretation with the concept of conditional probability (Q.5 to Q.12): The following acronyms, event $S$, DS, SH, W, SW, SC, C and SCD were already defined in the Method section. With those definitions, the simplified forms were interpreted in the following way: the ' $\mathrm{P}(\mathrm{S} \mid \mathrm{SH})=0.103$ ' indicates that $10.3 \%$ of respondents who felt slightly hot, regarded the sense of being slightly hot as a thermal comfortable feeling (thermal satisfaction). The results from Question 5 to 12 were summarized in Table 2. When Indonesian respondents imagined 'slightly cold $_{I}$ ' in their mind, this term was closer to a thermal comfortable feeling $[\mathrm{P}(\mathrm{S} \mid \mathrm{SCD})=0.571]$, rather than being a thermal uncomfortable feeling $[\mathrm{P}(\mathrm{DS} \mid \mathrm{SCD})=0.198]$, while for Japanese respondents the term 'slightly cold' was generally cognized as a feeling of thermal discomfort $[\mathrm{P}(\mathrm{S} \mid \mathrm{SCD})=0.085 ; \mathrm{P}(\mathrm{DS} \mid \mathrm{SCD})=0.699](\mathrm{Q} .7$, Table 2). Under the presupposition of being thermally uncomfortable in hot weather, only $6 \%$ of Japanese respondents selected the term ' $w^{2} \mathrm{rrm}_{\mathbf{J}}$ (in this case, the sum of 'slightly warm' and 'warm') as their presumed thermal sensation: P(SW,W|DS) (Q.9). On the other hand, in the case of being thermally comfortable in cold weather, $80 \%$ Japanese respondents selected the descriptor 'warm,' (in this case, the sum of 'slightly warm' and 'warm') as their presumed thermal sensation: $\mathrm{P}(\mathrm{SW}, \mathrm{W} \mid \mathrm{S})$. Group differences between Indonesian and Japanese for questions 5 to 12 were all statistically significant $(P<0.001$, Table 2).

A feeling of between 'neutral' and 'cold' (Q.13) and between 'neutral' and 'hot' (Q.14): For English respondents, the word describing the feeling between 'neutral' and 'cold' was 'cool' (56\%), and the word between 'neutral' and 'hot' was 'warm' (69\%). Indonesians responded that the term ' ${ }^{\circ}{ }_{1}{ }_{I}^{\prime}$ ' (62\%) is the best 
word to describe the feeling between 'neutral' ' and 'cold,', while both 'slightly cold,' (44\%) and 'cool J' (41\%) were selected for Japanese with the highest percentages (Fig. 4). In a similar way, Indonesians responded that the term ' warm $_{\mathbf{I}}$ ' $(52 \%)$ is the best word to describe their feeling between 'neutral ${ }_{I}$ ' and 'hot ${ }_{I}$ ', while for Japanese 'slightly hot' (42\%) and 'warm, (37\%) showed the highest percentages among the 11 thermal descriptors of the example box. The group differences in Question 13 and 14 were all statistically significant $(P<0.001)$

The most opposite word to 'warm' (Q.15): The most opposite word to 'warm' was 'cool' for English (82\%), Japanese (71\%) and Indonesian (71\%) respondents, but the frequencies of responses showed a significant difference between Japanese and Indonesians $(P<0.001)$. 25\% of Japanese considered that the term 'cold $\mathbf{J}_{\mathbf{J}}$ ' is the most opposite word to 'warm J', while only $4.8 \%$ of Indonesians responded that the term 'cold ${ }_{\mathbf{I}}$ ' is the opposite word to 'warm?'.

Air temperatures judged as hot and cold weather in the mind (Q.16 and Q.17): 44\% of Japanese respondents selected the 'higher than $29^{\circ} \mathrm{C}$ ' as hot weather, followed by 'higher than $32^{\circ} \mathrm{C}$ ' (30\%), while $33 \%$ of Indonesians considered 'higher than $32^{\circ} \mathrm{C}$ ' as hot weather, and $21 \%$ of Indonesians expressed 'higher than $35^{\circ} \mathrm{C}$ ' as hot weather (Fig. 5). For cold weather, most Japanese respondents considered 'lower than $15^{\circ} \mathrm{C}$ ' (44\%) and 'lower than $10^{\circ} \mathrm{C}$ ' (33\%) as cold weather, while the 55\% of Indonesians responded 'lower than $20^{\circ} \mathrm{C}^{\prime}$ as cold weather. Through a composite analysis of Question 16 and 17, a mentally presumed inter-zone between hot and cold weather was estimated with a limitation that those questions were asked with categorical variables in temperature. As a result, Japanese respondents considered hot weather as higher than $30.1^{\circ} \mathrm{C}$ (SD 2.8) and cold weather as lower than $13.1^{\circ} \mathrm{C}$ (SD 4.4). Indonesians considered higher than $32.4^{\circ} \mathrm{C}$ (SD 3.5) and lower than $16.5^{\circ} \mathrm{C}$ (SD 5.2) as hot and cold weather, respectively. English respondents considered higher than $29.8^{\circ} \mathrm{C}$ (SD 3.0) and lower than $8.5^{\circ} \mathrm{C}$ (SD 4.5) as hot and cold weather, respectively.

\section{Discussion}


The evidence of heat acclimatization in Indonesian language appears on the cool side thermal descriptors, not on the warm side.

Our hypothesis was that the closest descriptor among thermal descriptors for Indonesians of a feeling of thermal comfort is the term 'cool', and the hypothesis was multilaterally tested through a series of questions. First of all, 92\% of Indonesian respondents plainly stated that descriptors describing coolness or cold (the sum of votes on slightly cool, cool, slightly cold, and cold) are the closest words to a thermal comfortable feeling in their mind. This result is indeed noteworthy when compared to those of English (33\%) and Japanese (50\%) respondents. The 'coolı' for Indonesians was cognized as being thermally satisfied, irrespective of individual heat/cold susceptibility, whereas for Japanese the relationship between 'cool $\mathbf{J}_{\mathbf{J}}$ ' and a feeling of thermal comfort was dependent on whether the respondents were susceptible to either cold or heat. This means that the descriptor ' $\operatorname{cool}_{\mathbf{I}}$ ' for Indonesians is strongly conjoined with thermal comfort. In a similar way as discussed in Lee et al. (2009), the present results indicate that for Indonesians, 'comfortably cool' ' would sound like a redundant expression. Our hypothesis was also examined using a concept of conditional probability. The results of $\mathrm{P}(\mathrm{S} \mid \mathrm{C})=0.968, \mathrm{P}(\mathrm{S} \mid \mathrm{SCD})=0.571$, and $\mathrm{P}(\mathrm{C} \mid \mathrm{S})=0.709$ from Indonesian respondents underpin our hypothesis. It is of particular interest that the values of $\mathrm{P}(\mathrm{S} \mid \mathrm{SCD})$ and $\mathrm{P}(\mathrm{DS} \mid \mathrm{SCD})$ from Indonesians considerably differ from Japanese and English responses (Table 2). Such differences suggest that Indonesians possess a certain level of heat acclimatization in the words used to express thermal sensation. Furthermore, the result of $\mathrm{P}(\mathrm{DS} \mid \mathrm{C})=0.007$ strongly suggests that there are very few elements of thermal discomfort within the spectrum of ' $\mathrm{Cool}_{\mathbf{I}}$ ' for Indonesians, when compared to the response of the English $[\mathrm{P}(\mathrm{DS} \mid \mathrm{C})=0.256]$.

\section{Heat acclimatization induces an upward shift in the inter-zone between hot and cold weather in the mind.}

It is found that Indonesians project thermal comfort in the term ' $\mathrm{cool}_{I}$ '. It was, simultaneously, found that there was an upward shift in the air temperature level that is judged as cold weather in the mind for Indonesians. In other words, the most frequently voted choice in Question 17 was 'lower than $20^{\circ} \mathrm{C}$ ' as cold weather for Indonesians, whereas the Japanese and English respondents voted 'lower than $15^{\circ} \mathrm{C}$ ' and 'lower than $10^{\circ} \mathrm{C}^{\prime}$, respectively (Fig. 5). Such an upward shift of Indonesians is also found on the level of judged hot 
weather. As a consequence, the inter-zone between air temperatures of hot and cold weather has an equivalent range between Japanese and Indonesians. The current observations may provide some clues to understand how human thermal neutral zone is dynamically formed in the mind. It is speculated that for Indonesians the dominant preference to the term ' $\mathrm{Cool}_{\mathbf{I}}$ ' as a feeling of thermal comfort may cause a downward extension in thermal neutral zone in their mind, but such extension could be in practice offset by the upward shift of the air temperature level of cold weather that is judged in the mind. Therefore, it would be also conceivable to suppose that arctic indigenes will consider 'warm' as a feeling of thermal comfort but the air temperature level of hot weather that is judged in their mind will show a downward shift, when compared with the level of temperate or tropical indigenes. This assumption will be elucidated with further studies.

\section{For Japanese, thermal warmness is conjoined with thermal comfort.}

Thermal descriptors such as 'comfortably warm' and 'uncomfortably warm' are often found in thermal affective scales (Bedford, 1950; Havenith and Heus, 2004), but as discussed in Lee et al. (2009) and Lee and Tochihara (2010) those terms sound unnatural for Koreans. It is generally agreed that the Japanese and Korean language share a common linguistic root, showing a close affinity in structure and semantics. The current results conformed with the affinity in semantics. Both results of $\mathrm{P}(\mathrm{S} \mid \mathrm{W})=0.736$ and $\mathrm{P}(\mathrm{SW}, \mathrm{W} \mid \mathrm{S})=$ 0.803 showed similar values as that previously reported from Koreans $(\mathrm{P}(\mathrm{S} \mid \mathrm{W})=0.804$ and $\mathrm{P}(\mathrm{SW}, \mathrm{W} \mid \mathrm{S})=$ 0.707) in Lee and Tochihara (2010), which confirm that the term 'warm, projects thermal comfort. However, such a strong tendency was not found in Indonesians $[\mathrm{P}(\mathrm{S} \mid \mathrm{W})=0.514$ and $\mathrm{P}(\mathrm{SW}, \mathrm{W} \mid \mathrm{S})=0.471]$. Simultaneously, the results of $\mathrm{P}(\mathrm{DS} \mid \mathrm{W})=0.057$ and $\mathrm{P}(\mathrm{SW}, \mathrm{W} \mid \mathrm{DS})=0.055$ from Japanese also confirm that there are very few thermally uncomfortable elements within the spectrum of 'warms'.

On the other hand, Figure 4 suggests that 'slightly cold ${ }_{\mathbf{J}}$ ' and 'slightly hot ${ }_{\mathbf{J}}$ ' in Japanese have almost equivalent significances with 'cool,' and 'warm, while English and Indonesian respondents did not show such a tendency. When we recall that most frequently used categorical scales for the assessment of thermal sensation (e.g., ISO scales) do not possess the following terms: 'slightly cold' and 'slightly hot', it needs to be noted that Japanese use those terms 'slightly cold' and 'slightly hot' as frequently as they use 'cool' and 'warm' in their daily lives. Further investigation is needed to establish whether a more detailed spectrum in 
the usage of thermal descriptors for Japanese resulted from having a distinct four seasons or from other cultural factors.

\section{Intersubjectivity in linguistic heat acclimatization and behavioral thermoregulation}

Thus far, the above discussion indicates that when "I feel cool” is spoken in English, Indonesian or Japanese language, the implicated meaning would differ from one another. Indonesians have multiple dimensions in the term ' $\mathrm{cool}_{\mathrm{I}}$ ' with a comfortable dimension beneath the literal meaning of 'cool' in English. Our survey indicates that the implicated dimension is tacitly agreed among Indonesian individuals. This phenomenon is supported by previous research indicating that thermal and perceptual assessments are intertwined with psychological schema-based and socio-cultural processes (Knez and Thorsson, 2006; Stewart, 2007). Furthermore, this phenomenon can be explained by a concept of 'intersubjectivity'. Since the concept has been originally introduced from phenomenology, the term, intersubjectivity, has been lively discussing in the disciplines of cognitive science, linguistics, etc. with various definitions. The present study defines intersubjectivity as a commonly owned (shared) understanding on subjectivity among individuals, according to Ibáñez and Cosmelli (2008). The present study successfully disclosed that linguistic heat acclimatization is accomplished via a process of intersubjectivity, with an empirically testable hypothesis. Indonesian individuals have an intersubjective agreement in the meaning of the term ' $\mathrm{cool}_{I}$ ', but Japanese and English individuals do not. It is reasoned that the intersubjective agreement in language is formed through the long term heat exposure in their daily lives.

The approach to heat acclimatization in languages and semantics that is explained by intersubjectivity is an undeveloped and novel issue in thermal adaptive studies. Conventional studies on heat acclimatization have reported significant changes in heat-induced physiological responses such as sweating or body temperatures, and vice versa for cold acclimatization. One interesting finding of the current survey is, however, that linguistic heat acclimatization drives the cold side of thermal cognition, rather not than the warm side. On this account, one can speculate that linguistic heat acclimatization of Indonesians reflects a

cognitive preference for coolness in their daily hot weather. This point makes a difference between physiological and linguistic heat acclimatization. Physiological heat acclimatization exists as a causalitic 
entity within the human body, whereas linguistic heat acclimatization is projected onto the human mind as a preference within words. This should come as no surprise when we recall that linguistic heat acclimatization occurs at a cognitive level, not a perceptive nor a molecular level of individuals. As reminded by Haye (2008), human beings are not only living but also speaking beings. Every individual mind is monad, but it is reasonable to assume that the long-term heat exposure enables a commonly shared linguistic dimension from every monad. It seems that the linguistic elements in heat acclimatization are preserved in one's own language through intersubjective communication.

The intersubjectivity beneath the words to express thermal sensation will, therefore, be a tension driving our thermoregulatory behavior, such as drinking, eating, changing clothes, and seeking hospitable thermal environments. In this sense, the present approach on linguistic heat acclimatization has a peculiar account for exploring the thermoregulatory behavior of human being, which is not able to be investigated from animal research. A preference for coolness in tropical indigenes would be beneficial to drive the thermoregulatory behavior in tropical climates. Understanding of linguistic heat acclimatization will provide a new term to the model for the control of behavioral thermoregulatory responses.

\section{Limitations}

A number of factors limit the results of the current study. Firstly, one may raise a question on study design and purpose as follows: to investigate whether there are ethnic differences in linguistic dimensions, we should compare the different ethnic groups under an identical climate. In this regard, it should be noted that the present results are attributed to the combined effects of race, climates and culture on words expressing thermal sensation. A more sophisticated study design is needed to distinguish any single effect of race or climate on those words. Secondly, it is important to recall that most Indonesians respondents lack the direct exposure to cold weather. Due to the lack of exposure to cold weather, the linguistic heat acclimatization that was found on the words of the cool side should not be associated to the thermal adaptation to cold. Thirdly, the survey has been conducted in different seasons in English, Japan and Indonesians. Seasonal differences between the three countries may have given rise to differences that they reported even though respondents 
were well-informed that the questionnaire was asking about their general thoughts, irrespective of the particular season. Fourthly, the results of the sample from the UK cannot be generalized in further research, due to the small size of the sample. Further, it could be expected that the tendency of Japanese group will be between the English and the Indonesians due to the geographical location, but the small sample size of English respondents cannot meet such expectation. If the number of English respondents is increased, the results might be changed.

\section{Conclusions}

We proposed a new concept of heat acclimatization in languages to express thermal sensation. An empirical approach using a questionnaire was prototyped in the form of experimentally testable hypotheses to examine linguistic heat acclimatization. Our hypothesis was that the closest descriptor among thermal descriptors for Indonesians of thermal comfort is the term 'cool', and this hypothesis was multilaterally confirmed through a series of questions. The evidence of heat acclimatization in words for Indonesians appeared on the cool side of thermal descriptors, not on the warm side, which indicates that linguistic heat acclimatization reflects a preference for coolness in their daily hot weather. Such linguistic heat acclimatization can be explained with a concept of intersubjectivity. Simultaneously, it was found that there was an upward shift in the air temperature level that was judged as cold weather in the mind of Indonesians, when compared to those of English and Japanese respondents. The present approach unveiled the intersubjective nature of complex cognitive phenomena in terms of heat acclimatization, which is dependent on the interaction among the mind, thermal environment and culture. It seems that the intersubjective agreements in languages expressing thermal sensation are formed through the long term heat exposure in their daily lives. The preference for coolness is likely to be beneficial in driving thermoregulatory behavior in tropical climates.

\section{Acknowledgements}

The authors are indebted to Professor Tadakatsu Ohnaka for his helpful support in the survey. We would like to thank Dr. Muslim Mahardika, Dr. Nur Aini Masrurah, Sunu Wibirama, and Lasuardi Permana of Universitas Gadjah Mada, Indonesia. We would like to express our thanks to Dr. Hom B. Rijal and Eric A. Stone for their academic advice and support. This study was supported by Grant-in-Aid (No. 21247040) from the Japan Society for the Promotion of Science. 


\section{References}

ASHRAE (1992) Standard 55-Thermal environmental conditions for human occupancy. Atlanta: ASHRAE Inc

Bedford T (1950) Environmental warmth and human comfort. Br J App Physics 1(2): 33-38

Corbit JD (1970) Behavioral regulation of body temperature. In Hardy JD, Gagge AP, Stolwijk JAJ (eds)

Physiological and behavioral temperature regulation. Charles C Tomas: Illinois

Havenith G, Heus R (2004) A test battery related to ergonomics of protective clothing. Appl Ergon 35: 3-20

Haye AA (2008) Living being and speaking being: toward a dialogical approach to intentionality. Integr Psych Behav 42: 157-163

Hensel H (1973) Cutaneous thermoreceptors. In Iggo, A. (ed) Handbook of Sensory Physiology, Vol. II Somato Sensory System. p. 79-110: Berlin-Heidelberg-New York, Springer

Hensel H (1982) Thermal sensations and thermal receptors in man. Charles C Thomas Publisher, Illinois

Humphreys MA (2008) "Why did the piggy bark" some effects of language and context on the interpretation of words used in scales of warmth and thermal preference. Proceedings of Conference: Air Conditioning and the Low Carbon Cooling Challenge, Cumberland Lodge, Windsor, UK, 27-29 July 2008: Network for Comfort and Energy use in Buildings.

Ibáñez A, Cosmelli D (2008) Moving beyond computational cognitivism: understanding intentionality, intersubjectivity and ecology of mind. Integr Psych Behav 42: 129-136

Iggo A (1970) Ch.28. The mechanisms of biological temperature reception. In Hardy JD, Gagge AP, Stolwijk JAJ (eds) Physiological and behavioral temperature regulation. Charles C Tomas: Illinois

ISO 10551 (1995) Assessment of the influence of the thermal environment using subjective judgment scales. Geneva: International Standards Organization

IUPS Thermal Commission (2001) Glossary of terms for thermal physiology. Jap J Physiol 51(2): 245-280

Knez I, Thorsson S (2006) Influences of culture and environmental attitude on thermal, emotional and perceptual evaluations of a public square. Int J Biometeorol 50: 258-268

Lee JY, Tochihara Y (2010) Linguistic dimensions in descriptors expressing thermal sensation in Korean: warm projects thermal comfort. Int J Biometeorol 54(4):357-364

Lee JY, Bakri I, Toramoto S, Tochihara Y (2011a) Cutaneous thermal thresholds of tropical indigenes residing in Japan. Journal of Thermal Biology, 36: 461-468.

Lee JY, Saat M, Chou C, Hashiguchi N, Wijayanto T, Wakabayashi H, Tochihara Y (2010a) Cutaneous warm and cool sensation thresholds and the inter-threshold zone in Malaysian and Japanese males. J Therm Biol 35(2): 70-76

Lee JY, Stone EA, Wakabayashi H, Tochihara Y (2010b) Issues in combining likert and visual analog scales for the assessment of perceived thermal sensation: methodological and conceptual considerations. Applied Ergonomics 41:282-290 
Lee JY, Tochihara Y, Wakabayashi H, Stone EA (2009) Warm or slightly hot? Differences in linguistic dimensions describing perceived thermal sensation. J Anthrpol Physiol 28(1):37-41

Lee JY, Wakabayashi H, Wijayanto T, Hashiguchi N, Saat M, Tochihara Y (2011b) Ethnic differences in thermoregulatory responses during resting, passive and active heating: Application of Werner's Adaptation Model. Eur J Appl Physiol (DOI: 10.1007/s00421-011-1912-5)

Nadel ER, Mitchell JW, Stolwijk JAJ (1973) Differential thermal sensitivity in the human skin. Pflugers Arch. 340: $71-76$

Pitts A (2006) The language and semantics of thermal comfort. Proceedings of NCEUB Conference: Comfort and Energy Use in Buildings, Cumberland Lodge, Windsor, UK: Network for Comfort and Energy use in Buildings.

Saat MI, Tochihara Y (2008) Heat adaptation of tropic-dwelling people. J Human-Environ System 11(1): $7-12$

Schepers RJ, Ringkamp M (2009) Thermoreceptors and thermosensitive afferents. Neuroscience and Biobehavioral Reviews 33(3): 205-212

Stewart AE (2007) Linguistic dimensions of weather and climate perception. Int J Biometeorol 52:57-67

Taylor NAS (2006) Ethnic differences in thermoregulation: genotypic versus phenotypic heat adaptation. J Therm Biol 31: 90-104

Wakabayashi H, Wijayanto T, Lee JY, Hashiguchi N, Saat M, Tochihara Y (2011) Comparison of heat dissipation response between Malaysian and Japanese males during exercise in humid heat stress. Int $\mathrm{J}$ Biometeorol 55(4): 509-517

Wijayanto T, Wakabayashi H, Lee JY, Hashiguchi N, Saat M, Tochihara Y (2011) Comparison of thermoregulatory responses to heat between Malaysian and Japanese males during leg immersion. Int $\mathrm{J}$ Biometeorol 55(4): 491-500 
Table 1. English, Japanese and Indonesian words corresponding to each thermal descriptive term in questionnaire

\begin{tabular}{lll}
\hline English & Japanese & Indonesian \\
\hline Very hot & とても暑い & Sangat panas \\
Hot & 暑い & Panas \\
Slightly hot & やや暑い & Agak panas \\
Warm & 暖かい & Hangat \\
Slightly warm & やや暖かい & Agak hangat \\
\hline Neutral (Neither, & 暑くも寒くも & Tidak panas \\
Not hot or cold) & ない & ataupun dingin \\
\hline Slightly cool & やや涼しい & Agak sejuk \\
Cool & 冷たい & Sejuk \\
Slightly cold & や寒い & Agak dingin \\
Cold & 寒い & Dingin \\
Very cold & とても寒い & Sangat dingin \\
\hline
\end{tabular}

Table 2. Summary of responses to questions 5 to 12 in the questionnaire

\begin{tabular}{|c|c|c|c|c|c|c|}
\hline \multicolumn{2}{|c|}{ Question No. } & English & Japanese & Indonesian & $\chi^{2}$ & $P$-value \\
\hline 5 & $\begin{array}{l}\mathrm{P}(\mathrm{S} \mid \mathrm{SH}) \\
\mathrm{P}(\mathrm{DS} \mid \mathrm{SH})\end{array}$ & $\begin{array}{l}0.385 \\
0.385\end{array}$ & $\begin{array}{l}0.103 \\
0.723\end{array}$ & $\begin{array}{l}0.063 \\
0.666\end{array}$ & 29.6 & $<0.001$ \\
\hline 6 & $\begin{array}{l}\mathrm{P}(\mathrm{S} \mid \mathrm{W}) \\
\mathrm{P}(\mathrm{DS} \mid \mathrm{W})\end{array}$ & $\begin{array}{l}0.769 \\
0.103\end{array}$ & $\begin{array}{l}0.736 \\
0.057\end{array}$ & $\begin{array}{l}0.514 \\
0.172\end{array}$ & 63.9 & $<0.001$ \\
\hline 7 & $\begin{array}{l}\mathrm{P}(\mathrm{S} \mid \mathrm{SCD}) \\
\mathrm{P}(\mathrm{DS} \mid \mathrm{SCD})\end{array}$ & $\begin{array}{l}0.179 \\
0.615\end{array}$ & $\begin{array}{l}0.085 \\
0.699\end{array}$ & $\begin{array}{l}0.571 \\
0.198\end{array}$ & 331.9 & $<0.001$ \\
\hline 8 & $\begin{array}{l}\mathrm{P}(\mathrm{S} \mid \mathrm{CL}) \\
\mathrm{P}(\mathrm{DS} \mid \mathrm{CL})\end{array}$ & $\begin{array}{l}0.538 \\
0.256\end{array}$ & $\begin{array}{l}0.799 \\
0.026\end{array}$ & $\begin{array}{l}0.968 \\
0.007\end{array}$ & 80.1 & $<0.001$ \\
\hline 9 & $\begin{array}{l}\mathrm{P}(\mathrm{SH} \mid \mathrm{DS}) \text { in hot weather } \\
\mathrm{P}(\mathrm{SW} \mid \mathrm{DS} \text { or } \mathrm{W} \mid \mathrm{DS}) \text { in hot weather }\end{array}$ & $\begin{array}{l}0.359 \\
0.231\end{array}$ & $\begin{array}{l}0.396 \\
0.055\end{array}$ & $\begin{array}{l}0.503 \\
0.190\end{array}$ & 83.5 & $<0.001$ \\
\hline 10 & $\begin{array}{l}\mathrm{P}(\mathrm{SH} \mid \mathrm{S}) \text { in cold weather } \\
\mathrm{P}(\mathrm{SW} \mid \mathrm{S} \text { or } \mathrm{W} \mid \mathrm{S}) \text { in cold weather }\end{array}$ & $\begin{array}{l}0.077 \\
0.692\end{array}$ & $\begin{array}{l}0.020 \\
0.803\end{array}$ & $\begin{array}{l}0.028 \\
0.471\end{array}$ & 246.4 & $<0.001$ \\
\hline 11 & $\begin{array}{l}\text { P(SCL|DS or CL|DS) in cold weather } \\
\text { P(SCD|DS) in cold weather }\end{array}$ & $\begin{array}{l}0.051 \\
0.410\end{array}$ & $\begin{array}{l}0.039 \\
0.248\end{array}$ & $\begin{array}{l}0.121 \\
0.336\end{array}$ & 74.3 & $<0.001$ \\
\hline 12 & $\begin{array}{l}\mathrm{P}(\mathrm{SCL} \mid \mathrm{S} \text { or } \mathrm{CL} \mid \mathrm{S}) \text { in hot weather } \\
\mathrm{P}(\mathrm{SCD} \mid \mathrm{S}) \text { in hot weather }\end{array}$ & $\begin{array}{l}0.895 \\
0.000\end{array}$ & $\begin{array}{l}0.878 \\
0.013\end{array}$ & $\begin{array}{l}0.709 \\
0.074\end{array}$ & 84.3 & $<0.001$ \\
\hline
\end{tabular}

* The following abbreviations (S, DS, SH, SW, SCD, SCL, and CL) stand for 'satisfied, dissatisfied, slightly hot, slightly warm, slightly cold, slightly cool, and cool', respectively. $\chi^{2}$-analyses were tested with Japanese and Indonesian groups for each question. 


\begin{tabular}{|c|c|c|c|c|c|}
\hline Example Box & & & & & \\
\hline $\begin{array}{l}\text { (1) Very cold } \\
\text { (7) Slightly hot }\end{array}$ & $\begin{array}{c}\text { (2) Neutral (Not hot or cold) } \\
\text { (8) Hot }\end{array}$ & $\begin{array}{l}\text { (3) Cold } \\
\text { (9) Slightly cold }\end{array}$ & $\begin{array}{c}\text { (4) Cool } \\
\text { (10) Slightly warm }\end{array}$ & $\begin{array}{l}\text { (5) Very hot } \\
\text { (11) Warm }\end{array}$ & (6) Slightly cool \\
\hline
\end{tabular}

Q.4. Please select from the example box above, one word which is the closest description for YOU of a feeling of thermal comfort.

Q.5. Just imagine that YOU feel thermally 'Slightly hot' now. In this case, which one best describes YOUR feeling?

(1) I am generally satisfied with my thermal condition.

(2) I am generally dissatisfied with my thermal condition.

(3) I am neither satisfied nor dissatisfied with my thermal condition.

(4) I don't know.

Q.6. Just imagine that YOU feel 'Warm'. In this case, which one best describes YOUR feeling?

(1) I am generally satisfied with my thermal condition.

(2) I am generally dissatisfied with my thermal condition.

(3) I am neither satisfied nor dissatisfied with my thermal condition.

(4) I don't know.

Q.7. Just imagine that YOU feel thermally 'Slightly cold' now. In this case, which one best describes YOUR feeling?

(1) I am generally satisfied with my thermal condition.

(2) I am generally dissatisfied with my thermal condition.

(3) I am neither satisfied nor dissatisfied with my thermal condition.

(4) I don't know.

Q.8. Just imagine that YOU feel 'Cool'. In this case, which one best describes YOUR feeling?

(1) I am generally satisfied with my thermal condition.

(2) I am generally dissatisfied with my thermal condition.

(3) I am neither satisfied nor dissatisfied with my thermal condition.

(4) I don’t know.

Q.9. Just imagine it is a hot and humid summer. YOU walk out from an air-conditioned building to the hot and humid outside. At that moment, YOU feel 'a little thermally uncomfortable' but YOU do not sweat yet. YOUR thermal feeling would be ( ). Please select only one word from the above Example Box and insert the number in the blank parenthesis.

Q.10. Just imagine it is a cold and windy winter. YOU walk into a well-heated building from the cold and windy outside. YOU feel 'thermally comfortable' without any shivering. YOUR thermal feeling would be ( ). Please select only one word from the above Example Box and insert the number in the blank parenthesis.

Q.11. Just imagine it is a cold and windy winter. After staying in a well-heated building, YOU then walk out from the well-heated building to the cold outside. Outdoors, YOU feel 'a little thermally uncomfortable' with some goose bumps, but YOU do not

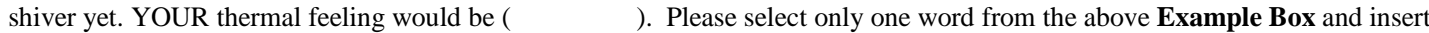
the number in the blank parenthesis.

Q.12. Just imagine it is a hot and humid summer. After walking in the street without any shade and sweating, YOU then walk into an air-conditioned building. Inside the building, YOU feel 'thermally comfortable'. At this moment, YOUR thermal feeling would be ( $\quad$ ). Please select only one word from the above Example Box and insert the number in the blank parenthesis.

Q.13. Which of the words below best describes a feeling of between 'neutral' and 'cold' when considering thermal environments? $\begin{array}{llll}\text { (1) Slightly cold (2) Slightly cool (3) Cool } & \end{array}$

Q.14. Which of the words below best describes a feeling of between 'neutral' and 'hot' when considering thermal environments? $\begin{array}{llll}\text { (1) Slightly hot } & \text { (2) Slightly warm (3) Warm }\end{array}$

$\begin{array}{llll}\text { Q.15. Which one is the most opposite word to 'Warm'? (1) Cold } & \text { (2) Slightly cold } & \text { (3) Cool } & \text { (4) (None) }\end{array}$

Q.16. What temperature do YOU consider as 'hot weather'? There is neither a correct nor an incorrect answer.

(1) higher than $26^{\circ} \mathrm{C}$ (2) higher than $29^{\circ} \mathrm{C}$ (3) higher than $32^{\circ} \mathrm{C}$ (4) higher than $35^{\circ} \mathrm{C}$ (5) higher than $38^{\circ} \mathrm{C}$ (6) higher than $40^{\circ} \mathrm{C}$

Q.17. What temperature do YOU consider as 'cold weather'? There is neither a correct nor an incorrect answer. $\begin{array}{lllllll}\text { (1) lower than } 20^{\circ} \mathrm{C} & \text { (2) lower than } 15^{\circ} \mathrm{C} & \text { (3) lower than } 10^{\circ} \mathrm{C} & \text { (4) lower than } 5^{\circ} \mathrm{C} & \text { (5) lower than } 0^{\circ} \mathrm{C} & \text { (6) lower than }-5^{\circ} \mathrm{C}\end{array}$

Fig. 1. Fourteen questions which were asked in the questionnaire. The original questionnaire was written in English, Indonesian and Japanese for each country. Questions 1 to 3 were to gain information on daily heating (Q.1), cooling habits (Q.2), and thermal susceptibility (Q. 3: I am highly sensitive to Cold, Heat, Both or Neither), which were not asked in the preliminary survey for the English. 


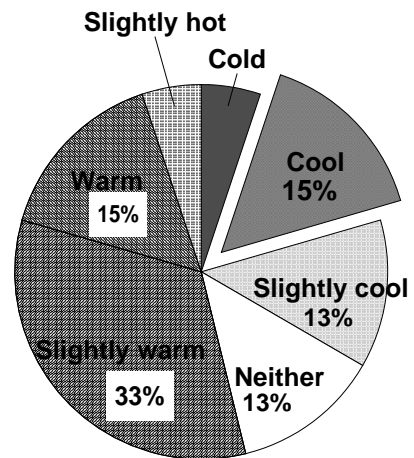

English ( $\mathrm{N}=39)$

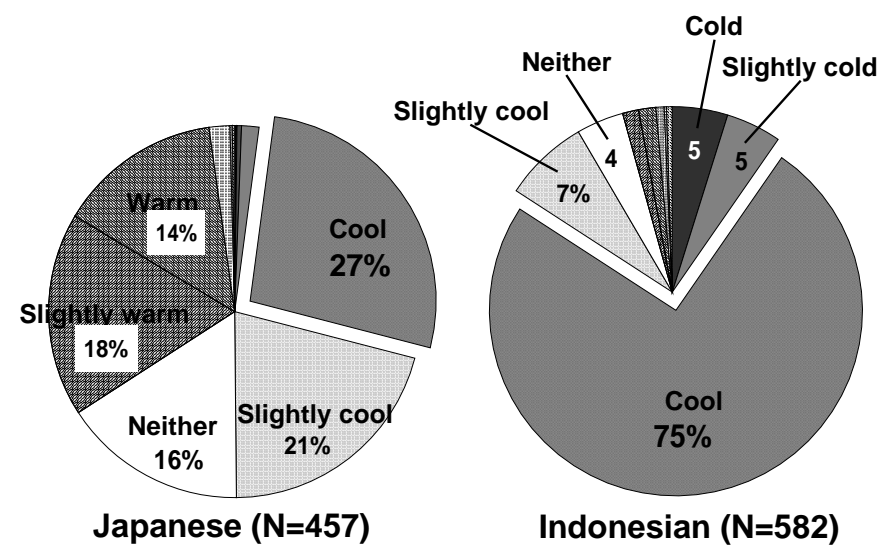

Fig. 2. Percentages of descriptors on the closest description of a feeling of thermal comfort (Question $4 ; \chi^{2}=$ 348.7 between Indonesian and Japanese groups, $P<0.001$; 'Neither' means 'Neutral (Not hot or cold)').

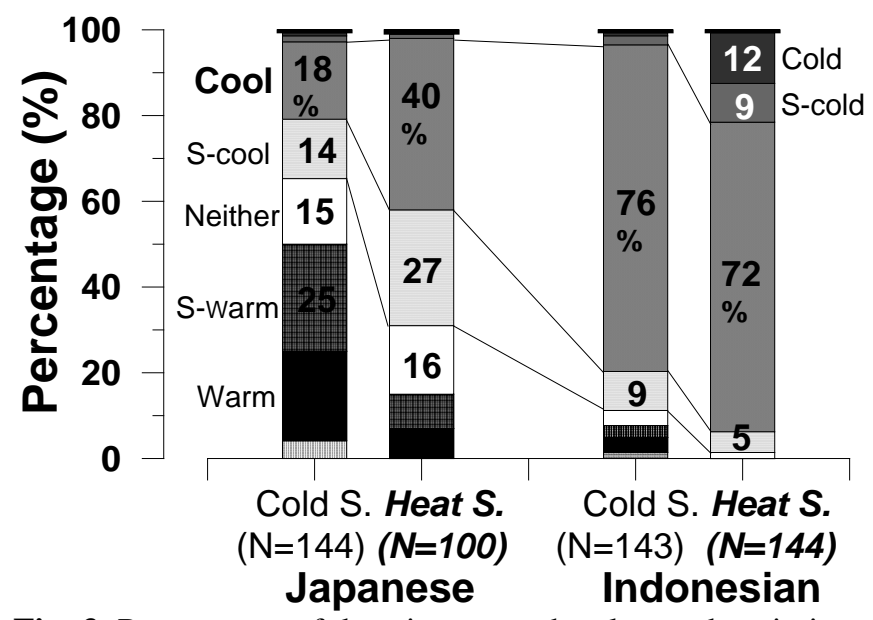

Fig. 3. Percentages of descriptors on the closest description of a feeling of thermal comfort (Question 4; $\chi^{2}=$ 348.7, $P<0.001$; 'Neither' means 'neutral (not hot or cold)'; 's-cold' stands for 'slightly cold'; 's-cool' for 'slightly cool'; 's-warm' for 'slightly warm'; 'Cold S.' for 'cold susceptible individuals'; 'Heat S.' for 'Heat susceptible individuals'. 
A.

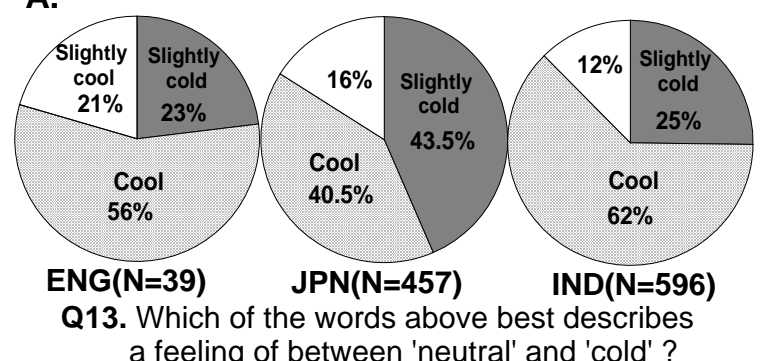

B.

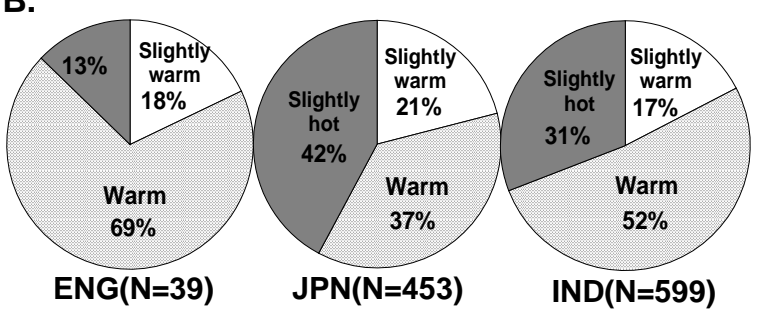

Q14. Which of the words above best describes a feeling between 'neutral' and 'hot' ?

Fig. 4. Percentages on thermal descriptors best describing a feeling of between 'neutral' and 'cold' (A-Question 13) and between 'neutral' and 'hot' (B-Question 14) for English (ENG), Japanese (JPN) and Indonesians (IDN) $\left(\chi^{2}=54.6\right.$ between Indonesian and Japanese groups, $P<0.001$ for Fig. 5A and $\chi^{2}=24.6$ between Indonesian and Japanese groups, $P<0.001$ for Fig. 5B).

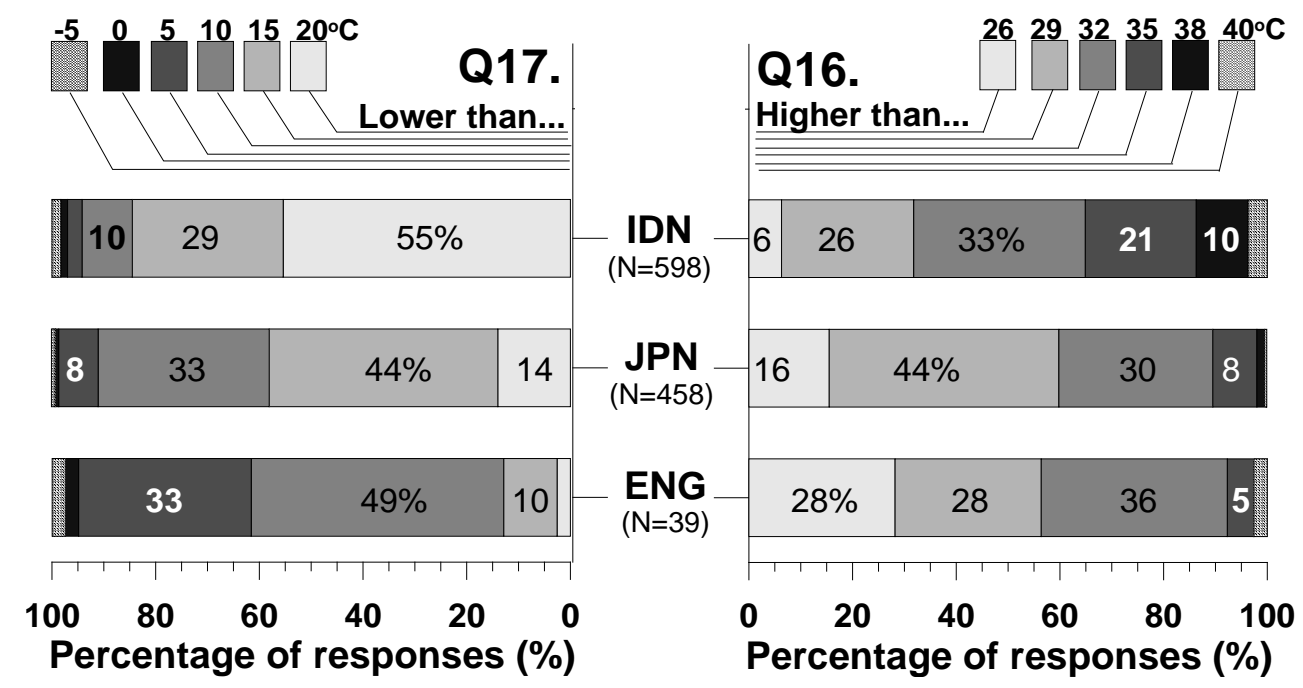

Fig. 5. Percentages of the air temperature that judged as hot (Right) and cold (Left) weather in mind $\left(\chi^{2}=\right.$ 117.8, $P<0.001$ for Question 16; $\chi^{2}=221.6$ between Indonesian and Japanese groups, $P<0.001$ for Question 17; ENG=English, JPN=Japanese, IDN=Indonesian). 